 \\ z Filologii Polskiej \\ i Słowiańskiej
}

DOI: $10.11649 /$ sfps.2014.016

\author{
Оксана А. Остапчук
}

(Филологический факультет Московского государственного университета им. М. В. Ломоносова),

Мадина М. Алексеева

(Институт славяноведения РАН, Москва)

\section{Многокомпонентные термины в функции ключевых слов в информационной базе славянского языкознания iSybislaw}

В 2014 г. исполняется 15 лет со времени первого издания Словаря ключевых слов 3. Рудник-Карват и Х. Карпинской (Rudnik-Karwatowa \& Karpińska, 1999). Словарь в первую очередь является эффективным инструментом, призванным облегчить поиск документов в информационно-поисковой системе славянского языкознания iSybislaw (Bibliograficzna baza danych językoznawstwa slawistycznego iSybislaw, n.d.; http://isybislaw. ispan.waw.pl), создаваемой международным коллективом славистов из разных стран, но при этом является также важным источником ценной лингвистической информации. С 2006 г. словарь существует также в электронной версии, которая была существенно расширена и дополнена

This is an Open Access article distributed under the terms of the Creative Commons Attribution 3.0 PL License (creativecommons.org/licenses/by/3.0/pl/), which permits redistribution, commercial and non-commercial, provided that the article is properly cited. () The Author(s) 2014.

Publisher: Institute of Slavic Studies, PAS \& The Slavic Foundation

[Wydawca: Instytut Slawistyki PAN \& Fundacja Slawistyczna] 
по сравнению с аналогичным книжным изданием (см. Rudnik-Karwatowa \& Karpińska, 2006; http://www.ispan.waw.pl/cnis/slownik_slow_kluczowych. $\mathrm{htm})$. Первоначально одноязычный, словарь стал основой развития и совершенствования электронной базы ключевых слов на разных славянских языках, действующей как принципиально открытая система. Настоящая статья основана на материале ключевых слов славянского языкознания в русском и польском языках и призвана, обобщив наш собственный опыт работы в системе iSybislaw (см. предыдущий абзац), осветить проблему поиска соответствий терминологических сочетаний в близкородственных славянских языках, особенно остро встающую в случае с многокомпонентными сочетаниями ${ }^{1}$.

Во вступлении к электронной версии словаря ключевые слова определяются как элементарные единицы информационно-поискового языка, совпадающие по форме с терминами, релевантными для данной области знания и способные представлять содержание конкретного документа (см. Rudnik-Karwatowa \& Karpińska, 2006; http://www.ispan. waw.pl/cnis/slownik_slow_kluczowych.htm; перевод наш - M.A., O.Ocm.). Особо останавливаются 3. Рудник-Карват и Х. Карпинская на критериях, которые учитывались при отборе терминов для словаря ключевых слов, среди них в качестве основных выделяются частотность, правильность, актуальность, лаконичность, структурная прозрачность. Добавим, что иерархия и вес этих критериев могут изменяться в зависимости от типа термина, его места в терминологической системе конкретного языка и роли в структуре текста отдельного документа.

С этой точки зрения особый интерес представляют многокомпонентные терминологические сочетания. По недавним статистическим подсчетам, в различных частных терминосистемах словосочетания составляют в настоящий момент от 39 до 54\% всех терминов (Ладзинь, 2008, с. 157), что делает насущной задачу включения многокомпонентных терминов как в традиционные терминологические словари, так и в поисковые базы данных. Многокомпонентный термин понимается нами как полилексемное терминологическое сочетание устойчивого типа (Кудинова, 2011, с. 59), как правило, с ядерным субстантивным комплексом. Заметим, что мы

1 Данная статья продолжает и развивает идеи, сформулированные в (Aleksiejewa \& Ostapczuk, 2011). 
рассматриваем как полилексемное сочетание с числом компонентов от двух и более. При структурной раздельнооформленности для этого вида терминов характерна терминологическая устойчивость и семантическая целостность, а также воспроизводимость, хотя степень идиоматичности может существенно различаться в зависимости от характера термино-единицы. Семантика таких сочетаний обнаруживает те же специфические черты, которые характерны для однословных терминов: подчеркнутая номинативная функция, тесная связь со специальным понятием в рамках конкретного раздела научного знания (Лейчик, 2006, с. 30), отсутствие стилистической (коннотативной) компоненты.

Включение многокомпонентных терминов в базу ключевых слов славянского языкознания происходит в полном соответствии с критерием актуальности. Большинство многокомпонентных терминологических сочетаний используется в относительно молодых, активно развиваемых, разделах науки о языке, таких как социолингвистика, психолингвистика, когнитивная лингвистика и под.: см., напр., такие термины, как языковое планирование - planowanie językowe, языковая политика - polityka językowa, aдресат сообшения - odbiorca komunikatu, языковое манипулирование - manipulacja jezykowa. Впрочем, и в традиционных разделах лингвистики (диалектологии, словообразовании и пр.) полилексемные (чаще всего двухкомпонентные) термины, несомненно, уже вошли в ядро частных терминосистем, как например, в семантике: семантическая валентность = walencja semantyczna, в грамматике: грамматическое значение = znaczenie gramatycznе, в морфологии: модальное слово = wyraz modalny, служебное слово = wyraz ротоспісzy, в фонетике: прогрессивная ассимиляиия = asymilacja postęроwa, акустический анализ = analiza fonetyczno-akustyczna и под.

Однако именно в связи с новыми терминологическими сочетаниями возникает проблема соотнесения частотности конкретного выражения и степени его идиоматичности. Очевидно, что именно высокая частотность и функциональная нагруженность терминологических сочетаний в научном дискурсе в целом и в конкретном документе в частности, обусловила включение в базу ключевых слов таких единиц, как консервативность языка - konserwatyzm językowy, нерегулярность в языке - nieregularność w języku, открытость языковой системы - otwartość systemu językowego, линейность языка - linearność języka, языковая магия - magia językowa. В свою очередь, препятствием для включения отдельных частотных, но 
слишком общих обозначений, может служить чрезмерная размытость их семантики (как в случае с примером семантизированная параллель и под.), в том числе в случае с «модными» сочетаниями типа дискурсивное слово, дискурсивный анализ и под. Дополнительным фактором, сдерживающим чрезмерное разрастание базы ключевых слов, является наличие устоявшегося термина с аналогичным значением, которому и отдается предпочтение: диалектологические исследования ср. диалектология, язык научного текста = язык научной речи ср. научный стиль. Одним из инструментальных критериев идиоматичности терминологического сочетания и способности его выступать в качестве ключевого слова в поисковой базе можно считать его соотнесенность с другими терминами и таксономическими категориями. В этом смысле противостоят друг другу, с одной стороны, дву- и многокомпонентные термины, обозначающие лингвистические понятия, соотносимые с другими аналогичными понятиями: функционально-семантическая категория = kategoria funkcjonalno-semantyczna (ср. грамматическая категория = kategoria gramatyczna), социолингвистический анализ = апаliza socjolingwistyczna (ср. грамматический анализ = analiza gramatyczna), a с другой - псевдотерминологические сочетания, за которыми не стоят особые концепты, напр., функиионально-семантическая сфера.

Важно подчеркнуть, что идиоматичность терминологического выражения, в том числе используемого как ключевое слово - проблема, выходящая за рамки одного языка. Реестр ключевых слов славянского языкознания, будучи принципиально открытой системой, включает в себя элементарные языковые единицы, совпадающие с терминоединицами разных языков. Заметим, что при составлении базы ключевых слов перевод не применяется, поиск функциональных соответствий в каждом из языков осуществляется независимо, исходя из содержания документа и места сочетания в конкретной терминологической системе. В дальнейшем для установления тождества слов или словосочетаний, имеющих в двух (или больше) языках узуально закрепленное идентичное или близкое терминологическое значение, ведущим принципом признается семантическая эквивалентность ${ }^{2}$. Установление отношений эквивалентности не исключает несимметричности формальной (не содержательной)

2 Ср. на примере правовой терминологии: (Козловская, 1997, с. 78). 
структуры терминов в разных языках: ср. язык поэзии / поэтический язык = język poetycki; язык меньшинства = język mniejszości / język mniejszościowy. Это касается, в частности, случаев выражения идентичных (чаще всего определительных) семантических отношений в разных языках при помощи различных структурных схем, ср.: текстовое слово = wyraz tekstowy; текстовая функция = funkcja tekstowa, НО текстовая струкmура / структура текста = struktura tekstu, схема предложения = schemat składniowy / schemat zdania. Определенные сложности в установлении отношений эквивалентности возникают в связи с морфологической оформленностью ядерного (субстантивного) элемента. В большинстве случаев словарной (исходной) формой термина признается терминологическое выражение с базовым существительным в форме единственного числа. Однако в связи с дискретностью ряда объектов номинации и спецификой обозначаемых понятий в базе славянского языкознания обнаруживаются также словосочетания с ядерным компонентом во множественном числе, см. напр., обозначения словообразовательных категорий: пол. nazwy osób, nazwy barw cp. pус. наименования / названия лии. Закрепленность за терминоединицами конкретной морфологической формы в одном из языков приводит к неполной (формальной) эквивалентности (Бархударов, 1975) при их межъязыковом сопоставлении. Так, например, по традиции в русской диалектологии принято употреблять обозначения территориальных разновидностей языка во множественном числе: орловские говоры, сибирские говоры и т.д. В свою очередь, согласно польской диалектологической традиции, минимальной территориальной единицей национального языка является gwara, соответственно, выделяется gwara łowicka, gwara łomżyńska и т.д., которая соотносится с единицей более высокого порядка dialekt - dialekt mazowiecki, wielkopolski и т.д. Однако при первичном членении диалектного пространства широко применяются также во множественном числе: gwary kieleckie, gwary kujawskie, таким образом, формы gwara kurpiowska - gwary kurpiowskie связывают, очевидно, родо-видовые отношения. Попытка соотнесения терминов разных языков приводит к вариативности терминоединиц на морфологическом уровне. Так, в польской части базы славянского языкознания в качестве соответствий для русских терминов приводятся синонимичные обозначения для диалектных явлений: gwary pskowskie / gwara pskowska / dialekt pskowski ср. псковские говоры / псковско-новгородский диалект, gwary staroobrzędowców = język staroobrzędowców cр. старообрядческие говоры. 
Особую проблему представляют здесь термины и терминологические сочетания, из-за специфики объекта исследования и различий в национальных подходах не находящие эквивалентов в других языках. В этой связи отдельно хотелось бы отметить диалектологические термины, в том числе касающиеся диалектного членения конкретных языков. Так, в русской диалектологии применяется одновременно два принципа номинации говоров: «конкретно-географический», согласно которому из диалектного массива вычленяются селигерские, поморские и под. говоры, и зональный, позволяющий говорить о северо-западных, юго-восточных и др. под. говорах. Термины зонального членения не имеют своих соответствий в польском языке из-за различий в национальных подходах к исследованию диалектного массива. К числу таких «безэквивалентных» терминов следует отнести также более общие термины диалектная зона; частная диалектная система - ключевые понятия для московской диалектологической школы, не использующиеся в других национальных школах и не имеющие устойчивых терминологических соответствий. Подобная ситуация наблюдается и в других частных терминосистемах, развивающихся в рамках конкретных национальных лингвистических школ. Так, лишь условным эквивалентом для активно применяемого в русской функциональной фонетике сочетания интонационная конструкция (ИК) можно считать польские терминоединицы kontur intonacyjny и intonacja zdaniowa. Учитывая особенности формирования национальной синтаксической терминологии, безэквивалентными следует признать рус. побудительное предложение и пол. zdanie życzace, несоотносимыми оказываются также термины рус. номинативное предложение и пол. bezorzeczeniowa konstrukcja nominatywna, рус. обособленная конструкиия и пол. ароzусја. Подобные проблемы возникают также при сопоставлении терминоединиц русского и польского языков в сфере социолингвистики. Так, из-за наличия расхождений в содержательном плане и указания на специфические объекты национальной языковой ситуации следует признать фактически безэквивалентными термины рус. городское просторечие, пол. gwara miejska, а также используемые для описания чешской языковой ситуации обиходно-разговорный язык, украинской - суржик, белорусской - трасянка.

Критерии частотности и актуальности, применяемые к конкретному языковому материалу, способствуют созданию репрезентативной базы ключевых слов в каждом из используемых в системе iSybislaw языков. 
При этом в рамках отдельных терминологических систем наблюдается избирательность в отношении базового элемента в составе многокомпонентных сочетаний: ср. признаваемые эквивалентными в базе ключевых слов рус. профессиональный жаргон и пол. gwara zawodowa = żargon zawo$d o w y$. Вариативность терминологических сочетаний с использованием синонимичных базовых субстантивов демонстрирует не только повышенный интерес исследователей к конкретному объекту исследования, но и определенную неустойчивость парадигматических связей в рамках частных терминосистем: ср. компьютерный сленг, сленг наркоманов, сленг футбольных хулиганов, НО игровой жаргон, сетевой жаргон, военный жаргон, журналистский жаргон, язык падонкофб. Уровень разработанности соответствующего понятия и степень устойчивости терминологии при этом в разных языках могут быть разными: ср. рус. молодежный сленг = молодежньй жаргон и пол. gwara młodzieżowa = socjolekt młodzieżowy = język młodzieży = slang młodzieżowy, аналогично рус. студенческий жаргон и пол. gwara studencka $=$ socjolekt studenck $i=j e ̨ z y k$ studencki $=$ slang studencki. Распространенность синонимического ряда для обозначения конкретной социальной разновидности языка можно считать также косвенным показателем актуальности конкретного терминологического понятия в научном дискурсе и соответствующего явления в языковой действительности: ср. рус. преступное арго = уголовный жаргон и пол. gwara przestępcza = żargon przestępczy, а также синонимичные им тюремный жаргон = блатной жаргон = феня = воровской жаргон $=$ уголовный жаргон = gwara więzienna.

В целом специфика накопления актуального лингвистического материала в базе ключевых слов, опора на конкретные языковедческие документы и стремление к репрезентативности базы неизбежно приводят к появлению параллельных обозначений типа рус. язык художественного произведения, язык художественного текста, язык художественной литературы или пол. jezzk artystyczny, język literatury pięknej. В распространенных синонимических рядах отмечается семантический сдвиг, что связано, в частности, с вхождением терминов в разные логико-парадигматические ряды: актуальное членение предложения = темо-рематическая структура = коммуникативная перспектива высказывания = функциональная перспектива высказывания. Фактор частотности, будучи одним из ведущих при отборе терминов для базы ключевых слов, влияет на положение терминоединицы в синонимическом ряду. При этом различная употребимость 
конкретных терминологических сочетаний в разных языках естественным образом обусловливает различия в структуре синонимических рядов терминов при их общей эквивалентности. Так, если в русской паре актуальное членение предложения = темо-рематическая структура доминантой является первое из выражений, то в польском случае это соотношение будет обратным: struktura tematyczno-rematyczna = aktualne rozczłonkowanie $z$ dania; эквивалентом синонимической паре коммуникативная перспектива высказывания = функииональная перспектива высказывания в базе ключевых слов является лишь funkcjonalna perspektywa zdania.

Следует отметить распространенность в базе ключевых слов явления полной синонимии дублетного типа, как в случае с рус.: лексический состав = словарный состав, ср. пол. zasób leksykalny = zasób słownikowy, пол. nosiciel języka = rodzimy użytkownik języka (cp. pус. носитель языка). Разумеется, такие дублеты являются результатом развития национальных терминосистем за счет внутренних ресурсов конкретного языка, что создает определенные диспропорции при сопоставлении рядов терминов в базе на разных языках, ср. пол. konstrukcja składniowa = konstrukcja syntaktycznа и рус. синтаксическая конструкция, пол. gruра imienna $($ так в iSybislaw $)=$ gruра nominalna и рус. именная конструкция. Синонимичность конструкции может явиться, среди прочего, результатом варьирования формальной структуры терминологического сочетания, как в примерах: рус. язык поэзии = поэтический язык ср. пол. język poetycki= język poezji, рус. язык русинов = русинский язык ср. пол. język rusiński. В случае появления расхождений содержательного плана, в частности, несовпадения объема понятий, между терминологическими сочетаниями устанавливаются лишь отношения частичной синонимии, см. напр.: рус. язык прессы (пол. język prasy), рус. язык публицистики (пол. język publicystyki) и рус. язык масс-медиа (пол. język mediów). Из-за специфики семантики терминологических сочетаний случаи установления отношений частичной синонимии по причине различий коннотативного элемента содержания следует отнести скорее к исключениям. Так, например, даже термины литургический язык = язык богослужения можно признать лишь частичными синонимами, тем более обозначение сакральный язык будет равноценным им только с определенными оговорками (ср. jezzk liturgiczny $=$ język sakralny).

Характерной особенностью многословных терминологических сочетаний является прозрачность их формы и семантики (значение, как пра- 
вило, выводится из значений компонентов), а также их потенциальная соотнесенность с однословными терминами. Этот потенциал реализуется в базе славянского языкознания в форме конкуренции однословных и многокомпонентных обозначений для одного и того же лингвистического понятия. Причем, если в одних случаях возникающие отношения можно рассматривать как конденсацию, свертывание информации (пол. akt perlokucyjny // perlokucja cр. рус. перлокутивныцй акт // перлокуиия, пол. związek przynależności // przynależność), то в других случаях, особенно когда речь заходит о параллелизме заимствованного в своей основе термина и терминосочетания, образованного из исконных элементов конкретного языка, можно говорить скорее об обратном соотношении, диффузии, или развертывании информации (fleksja // odmiana wyrazów, ojkonim // nazwa miejscowa, optativus // tryb życzacy, terminologia // leksyka specjalna). При этом если однословные наименования в большей степени соответствуют критерию лаконичности, то многокомпонентные исконные сочетания отличает большая прозрачность формы. Разумеется, сама возможность конкуренции раздельнооформленных и цельнооформленных терминологических единиц (и соответствующих ключевых слов) для обозначения конкретного понятия существует лишь в рамках конкретного языка, не всегда находя соответствия в родственных языках, так, пол. терминосочетанию wyraz bliskoznaczny соответствует одиночный русский термин синоним.

Таким образом, отбор дву- и многокомпонентных терминологических сочетаний для многоязычной базы славянского языкознания iSybislaw происходит с учетом критериев частотности, актуальности, а также прозрачности формы и содержания в каждом из языков отдельно. Это создает определенные сложности при попытке установления отношений эквивалентности между ключевыми словами (и соответствующими терминами) в разных славянских языках, в том числе в польском и русском. При общей констатации того факта, что большинство терминов входят в состав группы семантических констант, обладающих постоянными соответствиями (являющихся полными эквивалентами) в различных языках (Урбанек, 1997, сс. 61-62), значительная часть многокомпонентных терминологических сочетаний в силу ряда причин попадает в группу с частичной эквивалентностью терминоединиц. Свои особенности в каждом из языков демонстрирует также распределение терминов в рамках синонимических рядов ключевых слов, а также распространенность и состав этих синонимических рядов. 
Оксана А. Остапчук, Мадина М. Алексеева Многокомпонентные термины в функции...

\section{Bibliography}

Aleksiejewa, M., \& Ostapczuk, O. (2011). Многокомпонентные термины в научном дискурсе и в информационной системе славянского языкознания iSybislaw: на примере русского и польского языков. Slavia Orientalis, 62(2), 275-284.

Bibliograficzna baza danych światowego językoznawstwa slawistycznego iSybislaw. (n.d.). Retrieved from http://www.isybislaw.ispan.waw.pl

Lukszyn, J., \& Gilewski W. et al. (Eds.). (1993). Tezaurus terminologii translatorycznej. Warszawa: Wydawnictwo Naukowe PWN.

Rudnik-Karwatowa, Z., \& Karpińska, H. (1999). Słownik słów kluczowych językoznawstwa slawistycznego. Warszawa: Slawistyczny Ośrodek Wydawniczy.

Rudnik-Karwatowa, Z., \& Karpińska, H. (2006). Słownik słów kluczowych językoznawstwa slawistycznego. Retrieved from http://ispan.waw.pl/cnis/slownik_slow_kluczowych.htm

Бархударов, Л. С. (1975). Язык и перевод: вопросы общей и частной теории перевода. Москва: Международные отношения.

Козловская, 3. (1997). Отношения переводческой эквивалентности: на материале государственно-правовой лексики русского и польского языков. In С. Сятковский, \& Т. С. Тихомирова (Eds.), Проблемы изучения отночений эквивалентности в славянских языках (рp. 75-85). Москва: Диалог-МГУ.

Кудинова, Т. А. (2011). К вопросу о природе многокомпонентного термина (на примере английского подъязыка биотехнологий). Вестник Пермского университета: российская и зарубежная филология, 2(14), 58-62.

Ладзинь, Т. А. (2008). Проблема идиоматичности терминов-словосочетаний на материале предметной области «права человека». Вестник Санкт-Петербургского университета, 9: Филология. Востоковедение. Журналистика, 2(2), 157-162.

Лейчик, В. М. (2006). Терминоведение: предмет, методы, структура. Москва: КонКом.

Урбанек, Д. (1997). Понятие переводческой эквивалентности и переводческая типология лексики. In С. Сятковский, \& Т. С. Тихомирова (Eds.), Проблемы изучения отношений эквивалентности в славянских языках (рр. 53-65). Москва: Диалог-МГУ.

\section{Bibliography (transliteration)}

Aleksiejewa, M., \& Ostapczuk, O. (2011a). Mnogokomponentnye terminy v nauchnom diskurse i v informatsionnoĭ sisteme slavianskogo iazykoznaniia iSybislaw: na primere russkogo i pol'skogo iazykov. Slavia Orientalis, 62(2), 275-284. 
Оксана А. Остапчук, Мадина М. Алексеева Многокомпонентные термины в функиии...

Barkhudarov, L. S. (1975). IAzyk i perevod: voprosy obshcheй i chastnoĭ teorii perevoda. Moskva: Mezhdunarodnye otnosheniia.

Bibliograficzna baza danych światowego językoznawstwa slawistycznego iSybislaw. (n.d.). Retrieved from http://www.isybislaw.ispan.waw.pl

Kozlovskaia, Z. (1997). Otnosheniia perevodcheskoĭ èkvivalentnosti: na materiale gosudarstvennopravovoĭ leksiki russkogo i pol'skogo iazykov. In S. Siatkovskiŭ \& T. S. Tikhomirova (Eds.), Problemy izucheniia otnosheniŭ èkvivalentnosti v slavianskikh iazykakh (pp. 75-85). Moskva: Dialog-MGU.

Kudinova, T. A. (2011). K voprosu o prirode mnogokomponentnogo termina: na primere angliŭskogo pod"'iazyka biotekhnologiǔ. Vestnik Permskogo universiteta: rossiǔskaia i zarubezhnaia filologiia, 2(14), 58-62.

Ladzin', T. A. (2008). Problema idiomatichnosti terminov-slovosochetaniĭ na materiale predmetnoŭ oblasti «prava cheloveka». Vestnik Sankt-Peterburgskogo universiteta, 9: Filologiia. Vostokovedenie. Zhurnalistika, 2(2), 157-162.

Leĭchik, V. M. (2006). Termonovedenie: predmet, metody, struktura. Moskva: KonKom.

Lukszyn, J., \& Gilewski W. et al. (Eds.). (1993). Tezaurus terminologii translatorycznej. Warszawa: Wydawnictwo Naukowe PWN.

Rudnik-Karwatowa, Z., \& Karpińska, H. (1999). Słownik słów kluczowych językoznawstwa slawistycznego. Warszawa: Slawistyczny Ośrodek Wydawniczy.

Rudnik-Karwatowa, Z., \& Karpińska, H. (2006). Słownik słów kluczowych językoznawstwa slawistycznego. Retrieved from http://ispan.waw.pl/cnis/slownik_slow_kluczowych.htm

Urbanek, D. (1997). Poniatie perevodcheskoĭ èkvivalentnosti i perevodcheskaia tipologiia leksiki. In S. Siatkovskiŭ \& T. S. Tikhomirova (Eds.), Problemy izucheniia otnosheniı̆ ékvivalentnosti v slavianskikh iazykakh (pp. 53-65). Moskva: Dialog-MGU.

\section{Multi-word terms as key-words in the iSybislaw database}

\section{Summary}

This article is devoted to the problem of the criteria on which multi-word terms should be selected and verified for the bibliographic database of Slavic linguistics publications iSybislaw. The text is based on Russian and Polish linguistic material. Such criteria as actuality, frequency, transparency of form 
Оксана А. Остапчук, Мадина М. Алексеева Многокомпонентные термины в функции...

are applied separately in each language and different sets and variability of terms in the each case are established. The authors examine also the reasons of formal and semantic asymmetry between Polish and Russian terminological units in the database.

Keywords: database; equivalency; iSybislaw; keyword; linguistic terminology; multi-word term; Polish language; Russian language

Ключевые слова: база данных; iSybislaw; ключевое слово; многокомпонентный термин; польский язык; русский язык; эквивалентность 